\title{
The harmony between architectural forms and structural
}

\section{Case Study: Burj Khalifa Dubai}

\author{
Mojgan GHORBANZADEH \\ Faculty of Architecture, University of Bojnord, Bojnord, Iran \\ mgh.186@gmail.com
}

\begin{abstract}
The Burj Khalifa Tower is the world's tallest structure, passing all previous height records such a project by necessity requires pushing current analysis, material, construction technologies, and building systems to literally new heights. However, as such a building height has never before been attempted, it is also necessary to ensure all technologies and methods used are of sound development and practice. As such, the designers sought to be able to use conventional systems, materials, and construction of aerodynamic shaping and wind engineering played a major role in the architectural massing and design of this multi-use tower, where mitigating and taming the dynamic wind effects was one of the most important design criteria set forth at the onset of the project design. This paper provides brief description of the tower structural systems, focuses on the key issues considered in construction planning of the key structural components and briefly outlines the execution of one of the most comprehensive architectural forms and structural in tall buildings.
\end{abstract}

Keywords: architectural forms, Burj Khalifa, structural components, dynamic wind effects.

\section{Introduction}

As part of everyday life our society inhabits buildings. People have an inherent need for functional spaces because we as a society are always moving forward, innovating, and seeking to improve our way of life. Looking back on history thousands of years ago, the early builders accomplished amazing feats for their time: The Egyptians built the great pyramids and the Romans became the world's most powerful empire by building aqueducts and stone roads to support their massive city and population. As increasing knowledge of construction practices flourished, so did the colossal accomplishments of man. With each marvel of engineering finished the architectural bar became higher and higher. Buildings became wonderful yet mysterious creations to gaze upon (see figure 1). When I see a skyscraper I think of them as beautiful enigmas encased in steel and concrete. Their beautify stems from never knowing what to expect. On the building's façade there is a certain architectural look. But on inside the structural system (call it the skeleton of the building that is not meant to be seen) can look vastly different and profoundly intriguing. Whenever you think you've seen all 
there is, you are stunned by another architectural creation that you did not think was possible

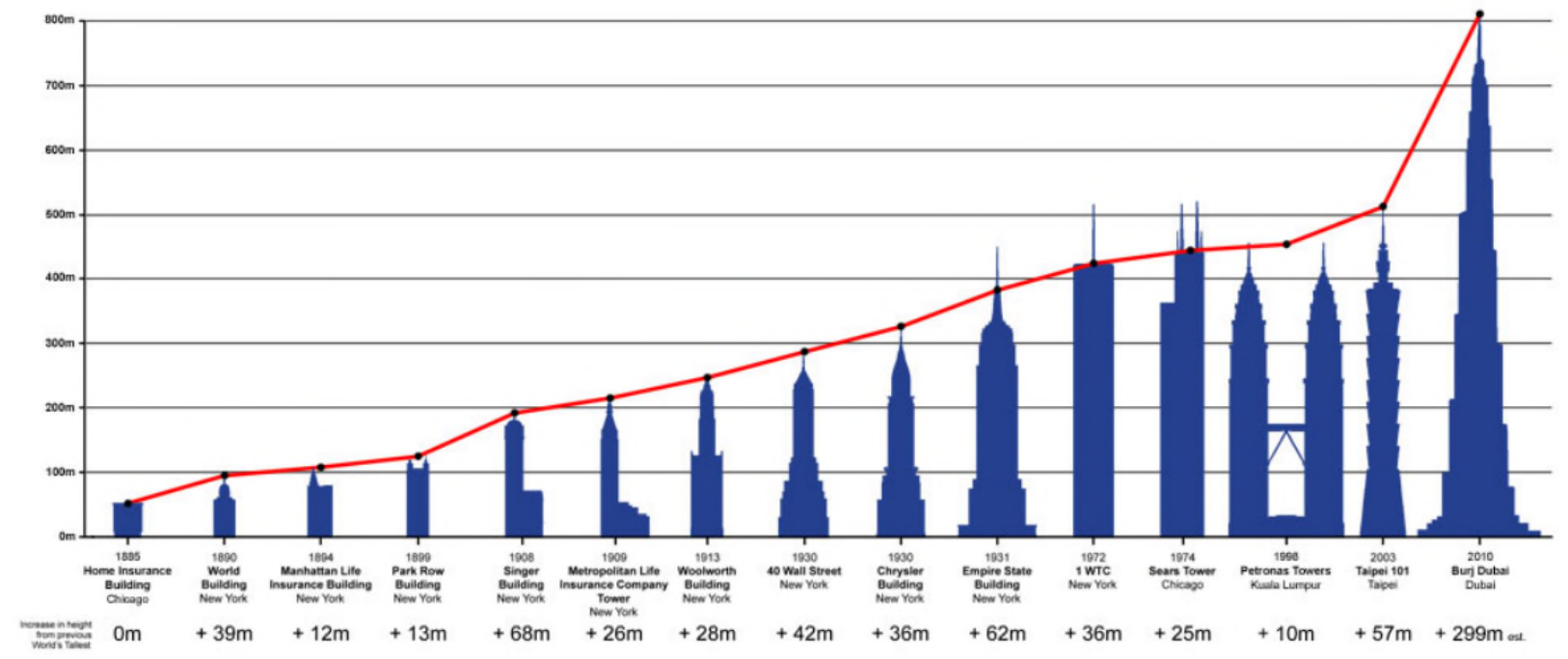

Figure 1: Diagram of all buildings that have at one time claimed the title of "World's Tallest Building" as of 2010 [1].

The Burj Khalifa in Dubai is a building of superlatives. At 828 meters (2,717 feet), it's the tallest in the world, 227 meters taller than No. 2, the Makkah Clock Royal Tower in Mecca. More than double the height of the Empire State Building, the 163-story building took six years, $\$ 1.5$ billion, 110,000 tons of concrete, and 22 million man-hours to build. But the most interesting thing about it isn't any of these incredible statistics but the way it looks: Unlike most supertall buildings, the Burj is nice to look at. It' s not a workmanlike stack of boxes, like the 442-meter Willis (née Sears) Tower in Chicago, or a postmodern heritage trinket like the Makkah Clock Tower, which resembles a Big Ben souvenir someone might buy at Heathrow [2].

\section{Structural Design}

The overall design of the tower came from the geometry of a desert flower indigenous to the region, the Hymenocallis, which resembles many Islamic architectural schemes. A view of the tower can be found in Figure 2. By design, this flower's "Y" shape, contributes to the tower's ability to minimize wind loads and creates a simple structural plan to follow throughout construction. Engineers first designed and constructed a unique foundation to accommodate the overlying massive tower (Figure 3) [3].

\subsection{Lateral Load Resisting System}

The tower's lateral load resisting system consists of high performance, reinforced concrete ductile core walls linked to the exterior reinforced concrete columns through a series of reinforced concrete shear wall panels at the mechanical levels. The core walls vary in thickness from $1300 \mathrm{~mm}$ to $500 \mathrm{~mm}$. The core walls are typically linked through a series of $800 \mathrm{~mm}$ to $1100 \mathrm{~mm}$ deep reinforced concrete or composite link beams at every level. Due to the limitation on the link beam depth, ductile composite link beams are provided in certain 
areas of the core wall system. These composite ductile link beams typically consist of steel shear plates, or structural steel built-up I-shaped beams, with shear studs embedded in the concrete section. The link beam width typically matches the adjacent core wall thickness.

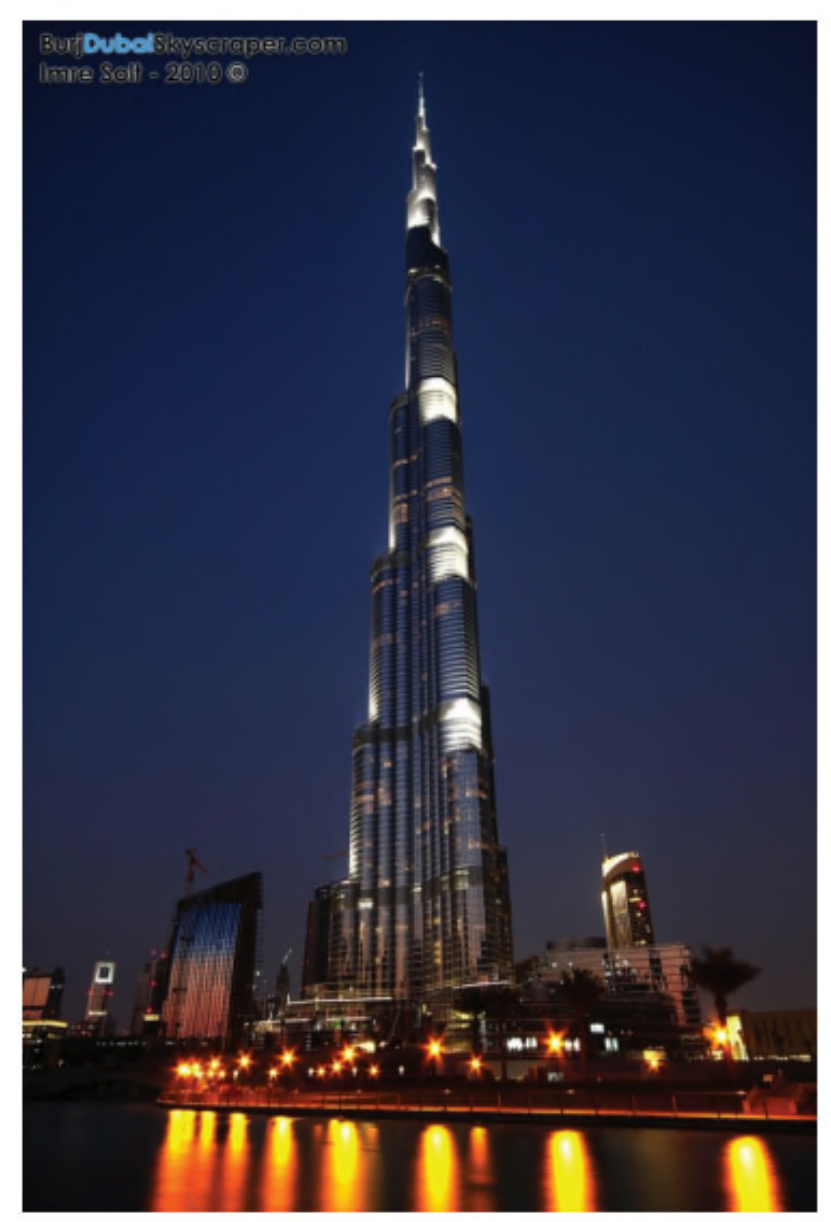

Figure 2: A view of the Burj Khalifa rising into the sky [3].

At the top of the center reinforced concrete core wall, a very tall spire tops the building, making it the tallest tower in the world for all categories. The lateral load resisting system of the spire consists of a diagonal structural steel bracing system at level 156 (see figure 4).

\subsection{Floor Framing System}

The residential and hotel floor framing system of the Tower consists of $200 \mathrm{~mm}$ to $300 \mathrm{~mm}$ two-way reinforced concrete flat plate slabs spanning approximately 9 meters between the exterior columns and the interior core wall. The floor framing system at the tips of the tower floor consists of a $225 \mathrm{~mm}$ to $250 \mathrm{~mm}$ two-way reinforced concrete flat plate system. The floor framing system within the interior core consists of a two way reinforced concrete flat plate system with beams [4]. 


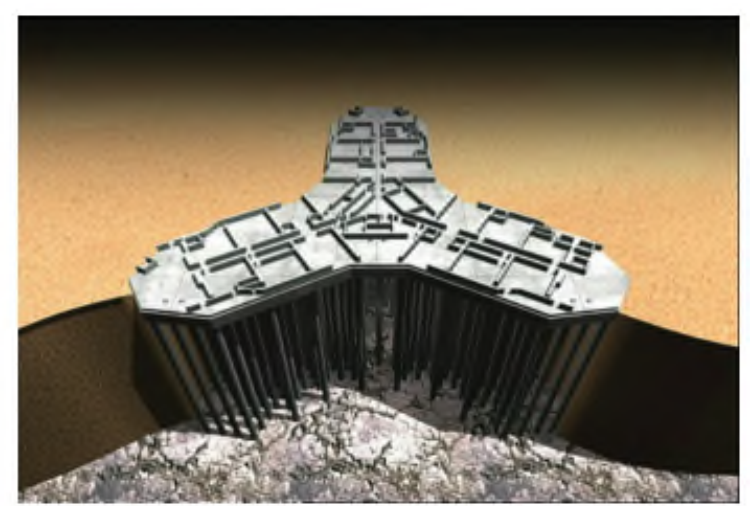

Figure 3: An elevation view of the tower's foundation system [3].

\section{Main Structure}

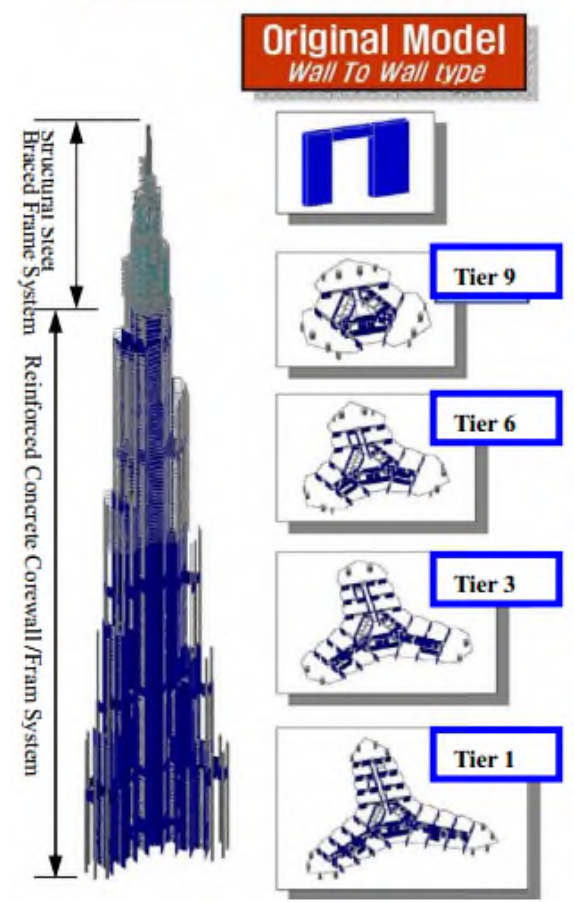

Figure 4: Lateral Load Resisting System [4].

\section{Construction Sequence Analysis Procedures}

The time-dependant effects of creep, shrinkage, the variation of concrete stiffness with time, sequential loading and foundation settlement were accounted for by analyzing 15 separate three-dimensional finite-element analysis models, each representing a discrete time during construction (Figure 5). At each point in time, for each model, only the incremental loads occurring in that particular time-step were applied. Additional time steps, after construction, were analyzed up to 50 years. The structural responses occurring at each timestep were stored and combined in a database to allow studying the predicted time-dependant response of the structure. 


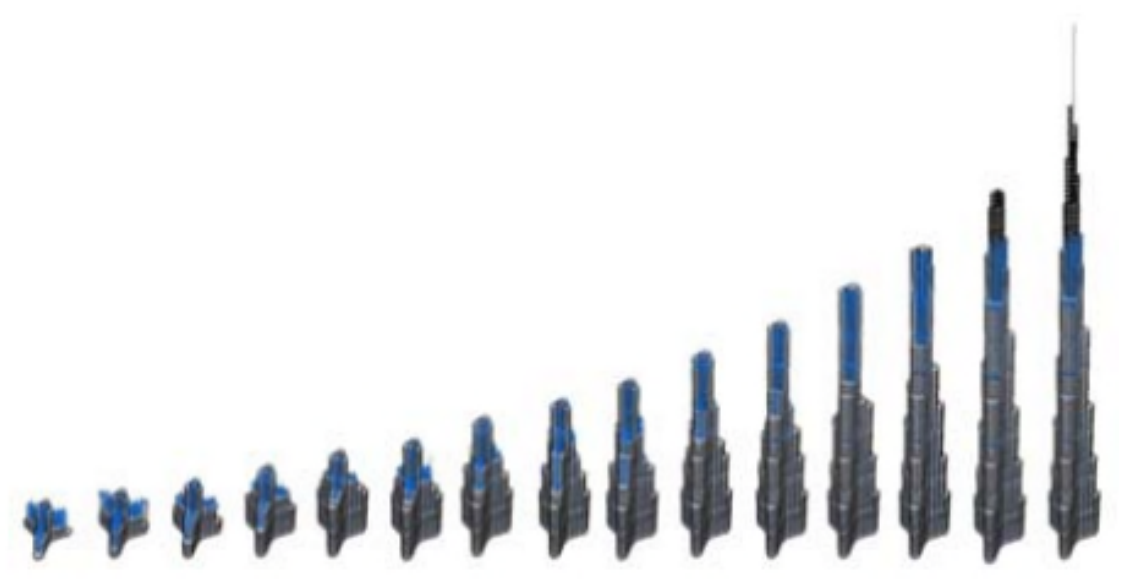

Figure 5: Construction Sequence Models [5].

Long-term creep and shrinkage testing, over one year in duration, have been performed, by the CTL Group (located in Skokie, IL) under contract with Samsung, on concrete specimens to better understand the actual behavior of the concrete utilized for the project.

\section{Compensation Methodology}

The tower is being constructed utilizing both a vertical and horizontal compensation program. For vertical compensation, each story is being constructed to a theoretical elevation incorporating a modest increase in the typical floor-to-floor height. This vertical compensation was selected to ensure the actual height of the structure, after the timedependant shortening effects of creep and shrinkage, will be greater than the as-designed final height. For horizontal compensation, the building is being "re-centered" with each successive center hex core jump. The re-centering compensation will correct for all gravity induced sidesway effects (elastic, differential foundation settlement, creep and shrinkage) which occur up to the casting of each story [5].

\section{Site Logistic Plan}

The Burj Khalifa site area is approximately $105,600 \mathrm{~m} 2$ and encompassing the tower, the office annex, the pool annex, and the parking areas, divided into three zones (Zone A, Zone $\mathrm{B}$, and Zone $\mathrm{C}$ ). The site logistic works and planning works are constantly evolving to reflect current construction activities, lay-down areas, site traffic circulation, etc.

\section{Tower Main Hoist}

Figure 6 depicts the location of the main hoists and the hoist specifications. The hoists were installed in three different phases following the construction sequence of the tower. Additional Jump hoists were installed in accordance with the specifications shown in figure $6[6]$. 

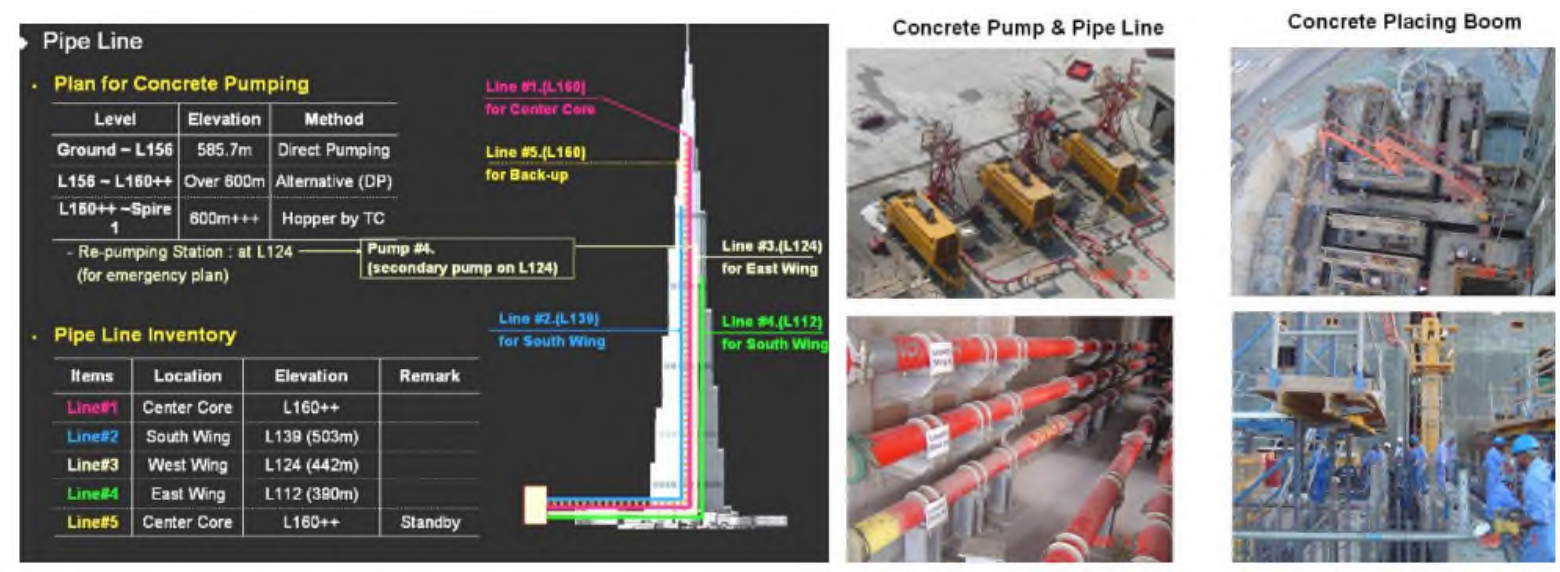

Figure 6 : Concrete Pumping Plan (Equipment, Pipe Lines, Cpb, Etc.)[6].

\section{Structural Health Monitoring \& Survey Program}

At the Burj Khalifa project, one of the most extensive structural health and survey monitoring program has been installed and it includes 1) more than 3000 strain gages at the columns, walls and beams, 2) foundation settlement survey, strain gages in the piles, horizontal and vertical survey system, accelerometers, and GPS system to monitor the dynamic behavior of the tower during construction and for permanent buildings conditions. Due to the limitation of the paper length, details of the monitoring system cannot be fully described here; however a special publication on the monitoring system of the Burj Khalifa project will follow [6].

\section{Architectural design}

The primary design concept of the tower is an organic form with tri-axial geometry and Spiraling growth that can be easily seen in the final design. Additionally, traditional Islamic forms were utilized to enrich the tower's design, and to incorporate visual references to the culture and history of the surrounding region. As such, the floor plan of the tower consists of a tri-axial, "Y" shaped plan, formed by having three separate wings connected to a central core.

\subsection{Burj Khalifa design idea}

Burj Khalifa Designed by SOM under the leadership of architect Adrian Smith, and soaring to $828 \mathrm{~m}$ (2,717 ft), Burj Khalifa in Dubai, UAE is very slender in form and silhouette and currently holds the title of the tallest building in the world. According to the architect Adrian Smith, the greatest source of inspiration for Burj Khalifa's form and geometry was a native desert flower, highly popular and widely cultivated in Dubai, and the filigree patterns 
of traditional Islamic architecture [7]. Named "Hymeocallis," it is a type of lily, is native to tropical Central America. Its flower structure is said to have provided the idea for the shape of the Burj Dubai's ground plan (see figure 7).

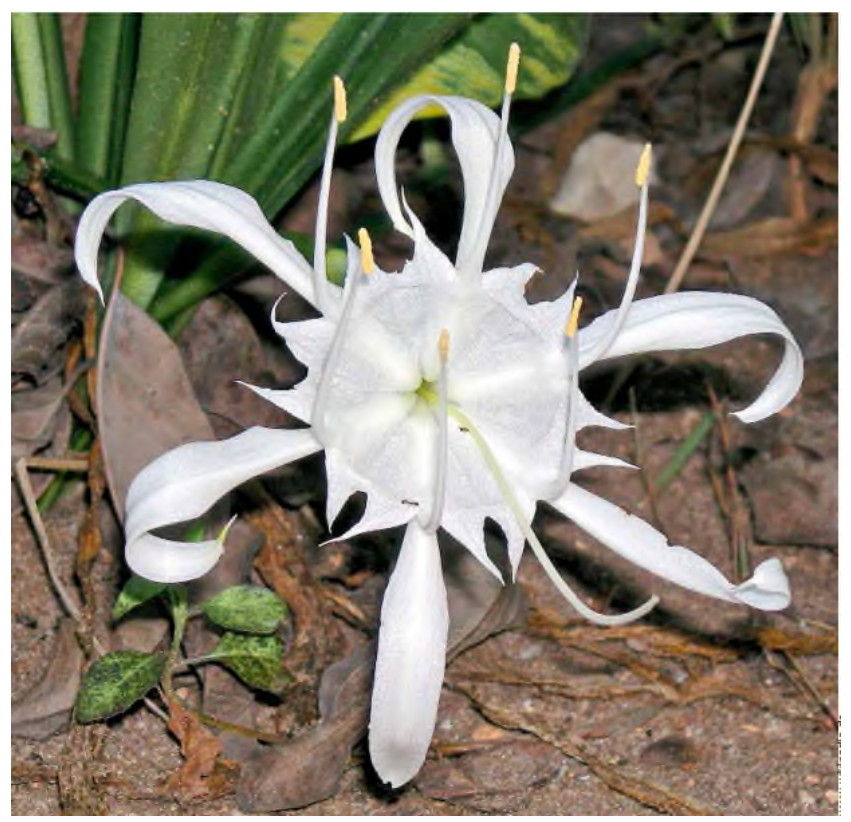

Figure7: flowers Hymenocallis [8].

The consumption figures for a building the size of the Burj Dubai (see figure 8) are impressive: the thermal energy that has to be extracted from the building at peak times each day would be enough to melt 10,000 tons of ice. The cooling water for the complex comes from two nearby cooling plants, each of which could service the Burj Dubai alone in case of emergency. The base of the building houses heat exchangers and pumping stations to provide the different user zones with cooling water: two each for the residential and hotel floors, one for the office floors and a further plant for cooling drinking water, whose temperature can rise to 39 degrees centigrade in the summer.

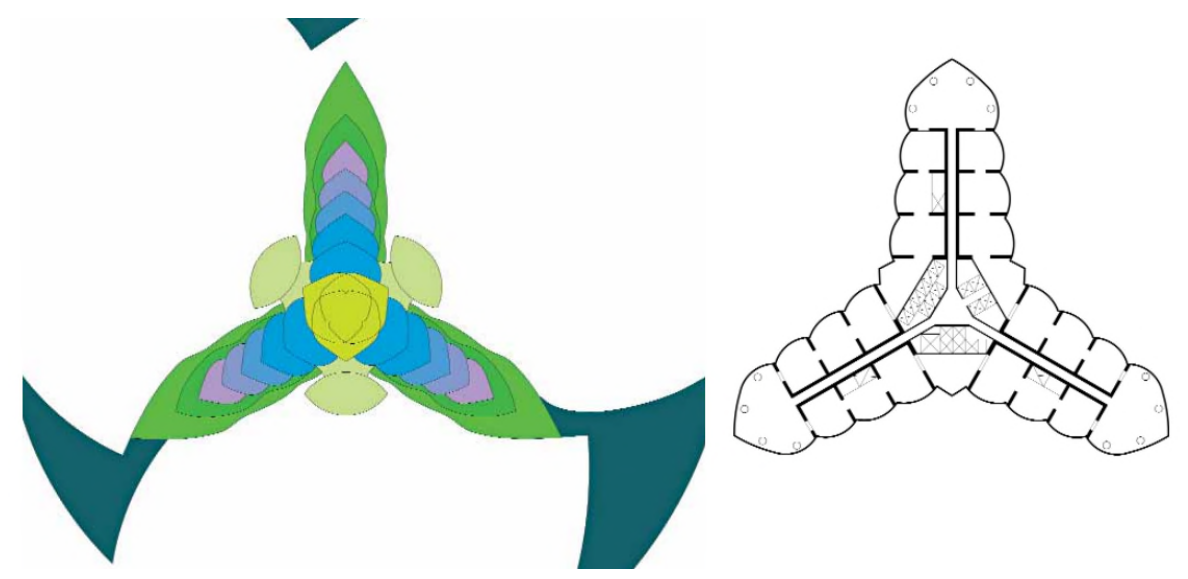

Figure 8: Top view of roof (left) and floor plan (right) [8]. 
The Burj Dubai is one of the first buildings in the Persian Gulf to have a $11 \mathrm{kV}$ supply. He power is not converted to a 230 volt operating voltage until it reaches the building's own transformer. 50 gas-insulated ABB switching units control the flow of current so precisely that sections of the building's full system can be isolated for maintenance purposes or to diagnose faults. This equipment is particularly suitable for use in high-rise buildings because it takes up so little space. As well as this, five $11 \mathrm{kV}$ emergency generators ensure that power can be supplied in emergencies for safety systems, selected lifts, pressure ventilation for the staircases, smoke removal ventilators, pumps and emergency lighting[8].

\subsection{First-rate installations}

The lift planners adapted a technique familiar from rail way systems for vertical access to the Burj Dubai: express lifts take residents and employees to distribution levels, so-called "sky lobbies", placed above the service zones, without stopping. From there, "local" lifts take users to their residential or office floor (see figure 9). The advantages: the express lifts can operate at very high speeds (up to 700 meters per minute) and with a high capacity ( 2 x 21 people on two cabin levels). In contrast with this, the shafts for the local lifts can be stacked one above the other to save space, as each of them serves only one section of the building[8].

\section{Coordination between structure and architecture}

As illustrated above, the architecture features atriple lobed footprint, an abstraction of the Hymenocallis flower. The tower is composed of three elements arranged around a central core. The modular, Y - shaped structure, with setbacks along each of its three wings provides an inherently stable configuration for the structure and provides good floor plates for residential. The central core emerges at the top and culminates in a sculpted spire. A Y shaped floor plan maximizes views of the Persian Gulf. This has led to Creates a special harmony between structure and architecture. 


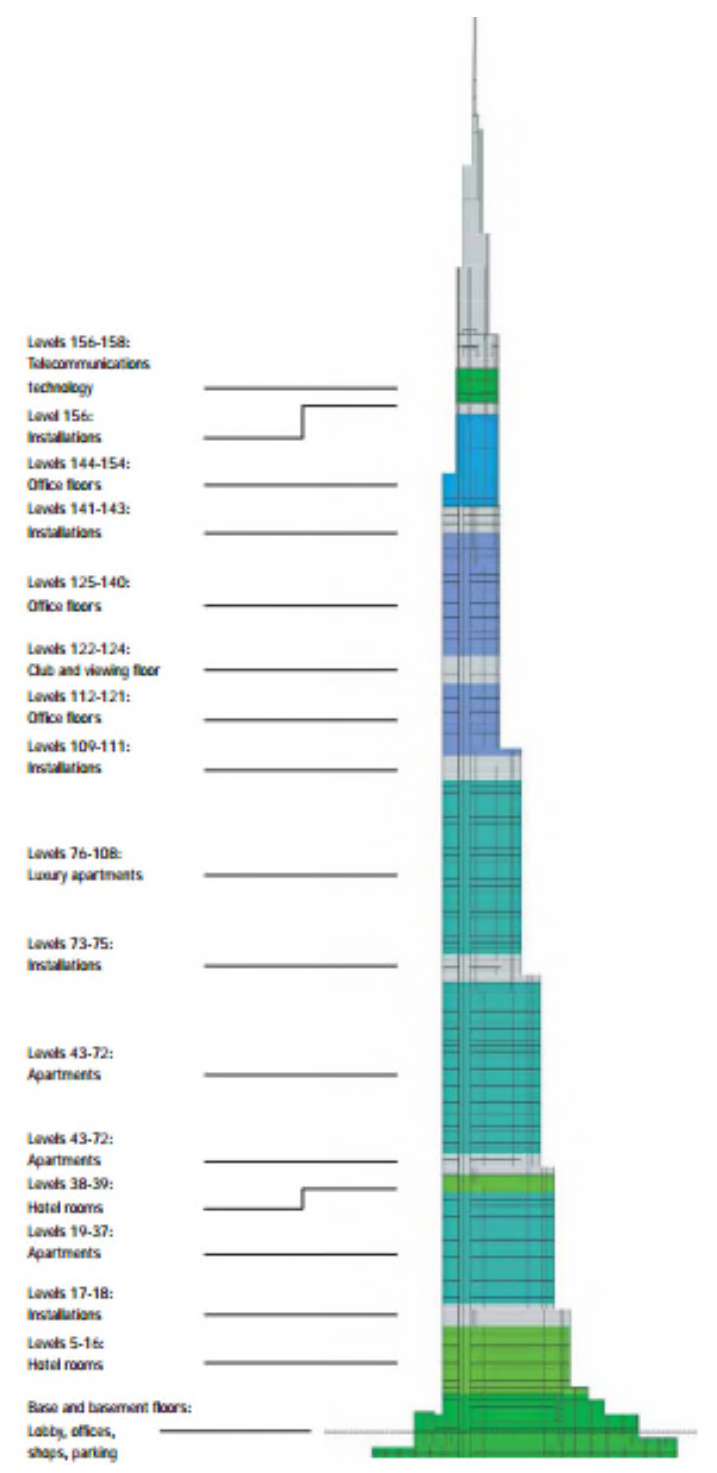

Figure 9: Burj Khalifa [8].

\subsection{Structure design Inspired by the architectural structures}

The tower's Y -shaped floor plan not only has aesthetic and functional advantages, but also is ideal for providing a high-performance, efficient structure. The structural system for the Burj Dubai can be described as a "buttressed-core" and consists of high-performance concrete wall construction (see figure 10). Each of the wings buttresses the others via a six-sided central core, or hexagonal hub. This central core provides the torsional resistance of the structure, similar to a closed pipe or axle. Corridor walls extend from the central core to near the end of each wing, terminating in thickened hammer head walls. These corridor walls and hammerhead walls behave similar to the webs and flanges of a beam to resist the wind shears and moments. 


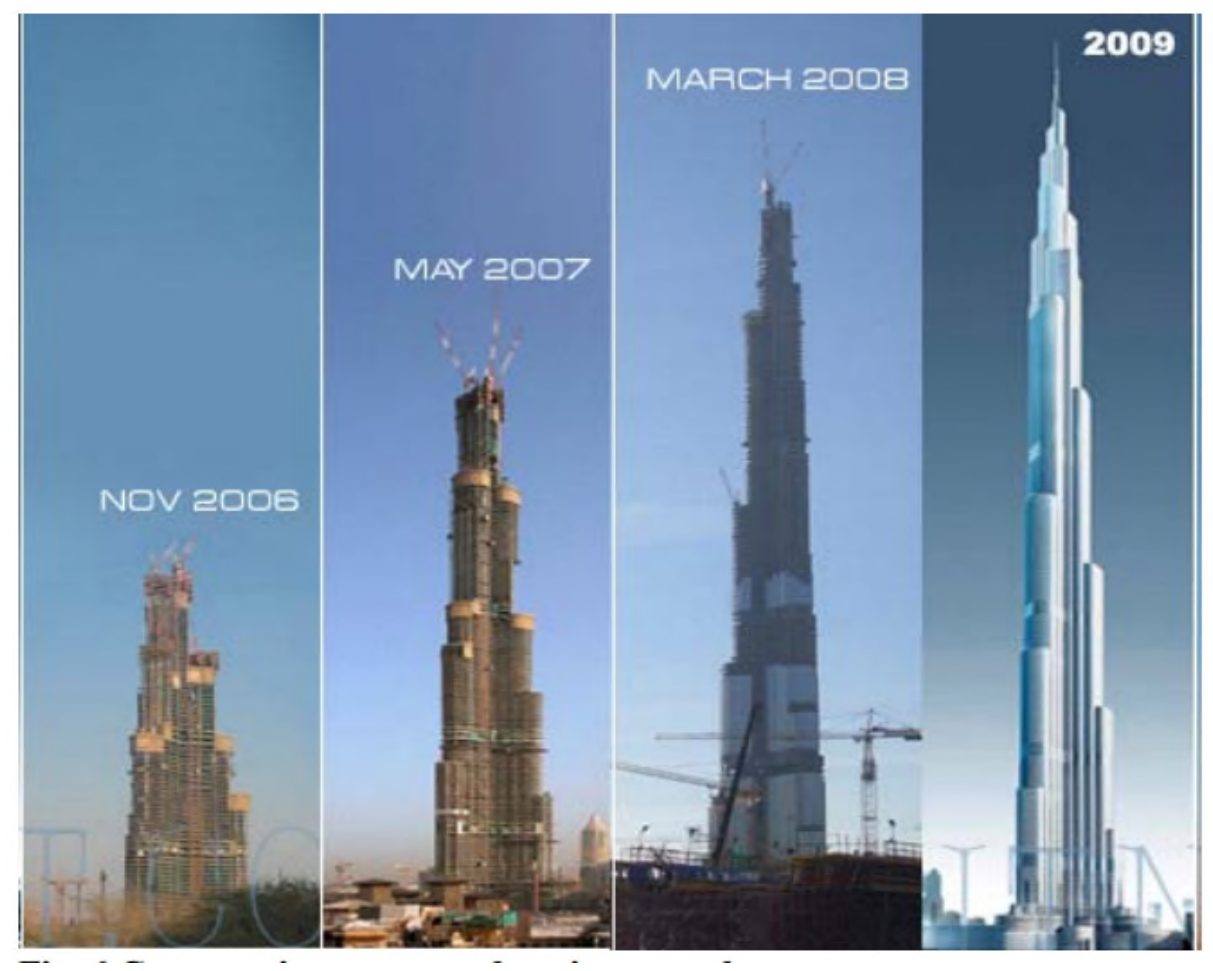

Figure 10 : Construction stages and setting records [9].

Perimeter columns and flat plate floor construction complete the system. At mechanical floors, outrigger walls are provided to link the perimeter columns to the interior wall system, allowing the perimeter columns to participate in the lateral load resistance of the structure; Hence, all of the vertical concrete is utilized to support both gravity and lateral loads.

The result is a tower that is extremely stiff laterally and torsionally. It is also a very efficient structure because the gravity load-resisting system has been used to maximize its use in resisting lateral loads also.

\subsection{Cladding of the tower}

The exterior cladding of Burj Khalifa is made of reflective aluminum and textured stainless steel spandrel panels with numerous small tubular fins. This design is supposed to resist the strong desert heat and solar rays better (see Fig 11). 28,261 glass panels, each individually hand-cut, were used in the exterior cladding. It is estimated that the exterior temperature at the top of the building will be $6{ }^{\circ} \mathrm{C}$ cooler than at its base. 


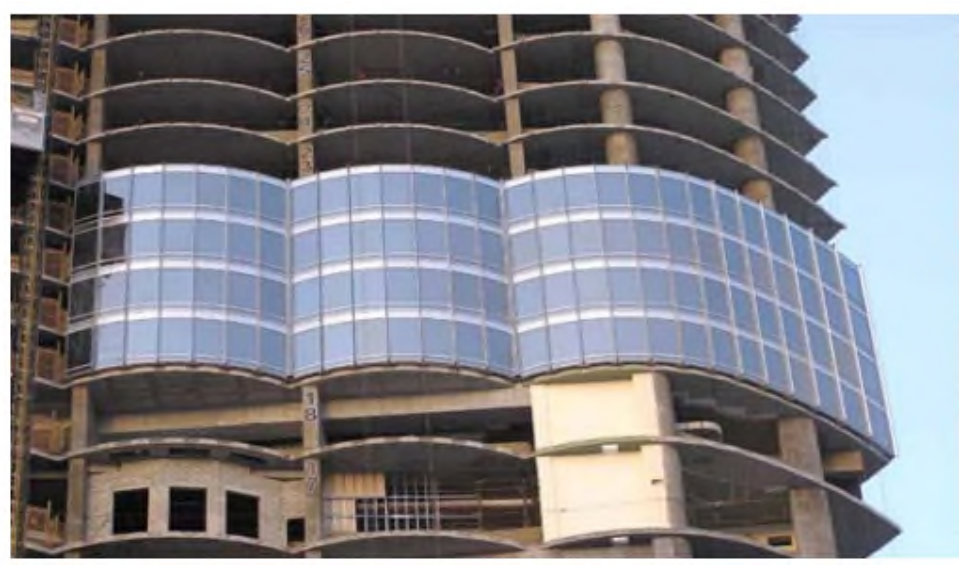

Figure 11: High performance exterior cladding system was used to withstand the extreme temperatures during the summer months in Dubai [9].

The tower is provided with 18 permanently installed track and fixed telescopic, cradle equipped, building maintenance units. These track mounted units, which are hidden when not in use, will be used for both window washing and exterior façade maintenance. Using these, the exterior may be accessed from the top down to level seven of the tower. Under normal conditions, and when all building maintenance units are in operation, it will take three to four months to clean the entire exterior façade [9].

\section{Conclusion}

On the 4th of January 2010, the opening ceremony of Burj Khalifa was held to celebrate the tallest man made structure in the world for at least the next decade. This project has made a new history in the world of architecture and engineering. The Burj Khalifa project by choosing The modular, Y-shaped structure, with setbacks along each of its three wings provides an inherently stable configuration for the structure and provides good floor plates for residential, Twenty-six helical levels decrease the cross section of the tower incrementally as it spirals skyward, The central core emerges at the top and culminates in a sculpted spire. An Y-shaped floor plan maximizes views of the Persian Gulf. Viewed from the base or the air, Burj Dubai is evocative of the onion domes prevalent in Islamic Architecture. All the above reasons had led to Creates a special harmony between structure and architecture. The Burj Khalifa project demonstrates that tall building system development is always directly related to the latest developments in material technologies, structural engineering theories, wind engineering, seismic engineering, computer technologies, and construction methods. The Burj Khalifa project capitalizes on the advancements in these technologies, and in advancing the development of supertall buildings and the art of structural engineering.

\section{References}

[1] Michael Soh. Past, Present, and Future: Building Sustainable Mega Skyscrapers. Journal Article for Illumni Magazine, WRIT 340, 2014. 
Bulletin de la Société Royale des Sciences de Liège, Vol. 86, special edition, 2017, p. 360 - 371

[2] Bryant Urstadt. Architects Gordon Gill and Adrian Smith on Building the W orld's T allest T owers. Bloomberg, 2014.

[3] Jonathan W eigand. Bringing to Life the World's Tallest Structure. The Journal of Undergraduate Research at the University of Tennessee, March 2013.

[4] Ahmad Abdelrazaq, S.E., Kyung Jun Kim and Jae Ho Kim. Brief on the Construction Planning of the Burj Dubai Project, Dubai, UAE. CTBUH 8th World Congress 2008.

[5] William F. Baker1, D. Stanton Korista2 and Lawrence C. Novak3. Engineering the World' s Tallest - Burj Dubai, CTBUH 8th World Congress, Dubai, 3-5 March 2008.

[6] Ahmad Abdelrazaq, SE. Design and Construction Planning of the Burj Khalifa, Dubai, UAE. 2010 Structures Congress @ 2010 ASCE.

[7] Kheir Al-Kodmany, Mir M. Ali. SKYSCRAPERS AND PLACEMAKING: SUPPORTING LOCAL CULTURE AND IDENTITY, International Journal of Architectural Research, July 2012.

[8] Skidmore, Owings and Merrill. The Ultimate Tower - Burj Dubai. The Journal of pulse movements in Architecture, 2008.

[9] Dr.N.Subramanian. BURJ KHALIFA, Worlds TALLEST STRUCTURE, NBM \& CW, Vol. 15, Jan 2010. 